\title{
Scrotal lymphangiomatosis: a case report
}

\author{
Rachel Wong; Megan Melnyk, MD; Steven S. Tang; Chris Nguan, MD, FRCSC
}

Department of Urologic Sciences, University of British Columbia, Vancouver, BC

Cite as: Can Urol Assoc J 2012;6(1):el 1-14. http://dx.doi.org/10.5489/cuaj.10139

\section{Abstract}

Lymphangiomas are benign tumours of the lymphatic system, and there are several reported cases of scrotal lymphangioma in the literature to date. We report a rare case of multilocular cutaneous lymphangiomatosis treated with surgical excision (total scrotectomy and reconstruction using split-thickness skin grafts with vacuum-assisted closure dressing).

\section{Case report}

A 39-year-old healthy male presented with a 20-year history of recurrent, complicated scrotal lymphangiomatosis. The lesions had previously been treated with local excision and cauterization, laser ablation and cryotherapy, but the lymphangiomas recurred quicker and denser in number following each treatment. The patient was referred to our urology clinic in 2007 with complaints of perineal pain. Physical examination demonstrated the scrotum itself was nodular and thickened with innumerable cutaneous lymphangiomas, with complete sparing of the penile skin. Following discussion with the patient, a continued conservative approach was initially exercised with antibiotic treatment and suppression of chronic scrotal cellulitis without surgical consideration of the lesions themselves. Despite this, the patient continued to suffer from recurrent infections of spontaneously ruptured lesions. Given the ineffectiveness of conservative therapy, the notable confinement of lymphangiomas to the scrotal skin (Fig. 1), and the ongoing psychological impact of the condition on the patient, a decision was made to escalate to surgical management consisting of total scrotectomy with reconstruction.

The patient was brought to the operating room, and following induction of general anesthesia, a "W" incision was made along the baseline such that the entire scrotum was incorporated while leaving skin $1 \mathrm{~cm}$ above the anus intact, thus forming a shape resembling the letter "W" (Fig. 2). The scrotum, including the epithelium, dermis, and superficial subcutaneous tissues, were dissected off using a combination of \#15 blade and the Metzenbaum scissors (Fig. 2). While the scrotectomy was being performed, the split-thickness graft was harvested from a shaved area on the right donor thigh. The Zimmer dermatome (Zimmer Inc., United Kingdom) set to $12 / 1000$ of an inch was used to harvest the skin graft, which was then meshed in a 1.5:1 fashion, and used to cover the area of defect. The borders of the graft were stapled in place, and then further quilted into place using 4-0 Vicryl sutures (Fig. 3). A vacuum-assisted closure (VAC) sponge was conformed to the skin-grafted area and reinforced with additional OpSite (Smith \& Nephew Healthcare, United Kingdom) dressings.

At one-month follow-up, there were a few small areas of delayed healing, overall good take of the graft, and no recurrence of scrotal lymphangiomatosis (Fig. 4). The shaft of the penis appeared to remain well-vascularized. The patient reported little pain, and was able to have normal erections with no chordee or deviation. The six-month follow-up showed almost complete healing, and no recurrence was observed (Fig. 5).

\section{Discussion}

Lymphangiomas are benign tumours of the lymphatic system and are thought to be the result of early developmental malformations, where lymph fails to drain into the central lymphatic channels and accumulates in the lymphatic vessels. ${ }^{1}$ The highest incidence of lymphangioma is during infancy, and most appear by age 30, with very few cases reported in later life. ${ }^{2}$ The condition affects males and females equally; it can be congenital or acquired, and the two are usually indistinguishable. ${ }^{2}$ Acquired lymphangioma can be a result of trauma, previous surgery, radiotherapy or filariasis. ${ }^{2}$ Lymphangiomas can be classified into three categories: (1) 


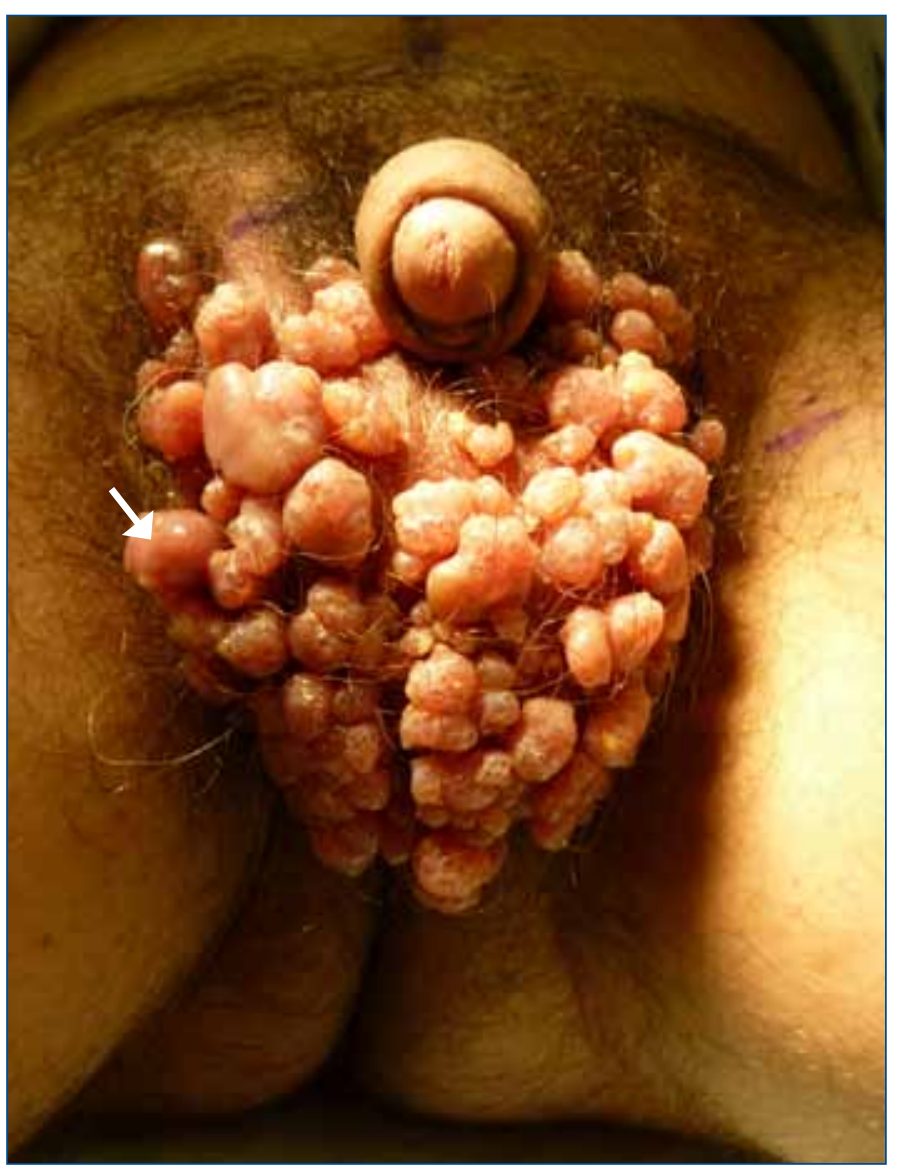

Fig. 1. Preoperative photograph showing the lymphangioma lesions on the scrotum.

capillary or simple lymphangiomas are thin-walled dilated vessels in a stroma of rich cellular connective tissue; (2) cavernous lymphangiomas have larger dilated lymphatics that are spongy and compressible, and may either be empty or filled with blood or lymph; and (3) cystic lymphangiomas, or cystic hydromas, are congenital macroscopic lymphatic that may intercommunicate or be separated by fibrous septa. ${ }^{3}$

Lymphangiomas occur most often on the posterior triangle of the neck or the axilla, but can also be found on all organs of the body except the brain, which lacks lymphatics. ${ }^{4}$ Although these lesions are benign, they are often chronic and predisposed to infections, which can cause patient discomfort and distress, and frequent lymphatic discharges from ruptured lesions require radical treatment. ${ }^{5}$ Superficial and small vesicular lesions can be treated with carbon dioxide laser, tunable dye laser, superficial x-ray and suction-assisted lipectomy, but have high rates of recurrences, and laser treatment can lead to keloid formation..$^{5,6}$ Because lymphatics are located within the dermis layer of the skin and the underlying dartos fascia, the complete excision of the subcutaneous tissues along with superficial lesions is vital in preventing recurrences. ${ }^{7}$ Surgical excision is the most effective method for treating extensive or deeply

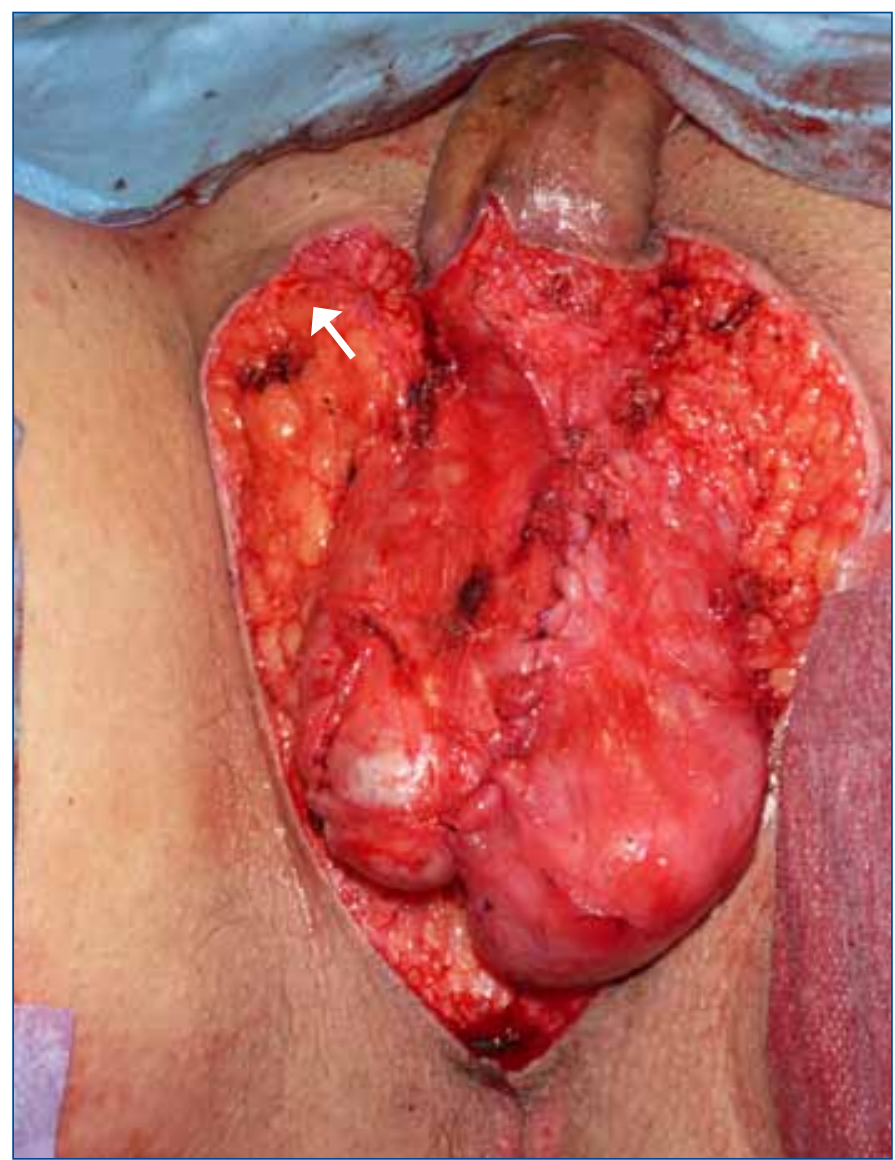

Fig. 2. Intraoperative photograph after the excision of the scrotum.

placed lesions. ${ }^{1-3,5,8-10} \mathrm{~A}$ survey of 80 patients with cutaneous lymphangiomas showed that $75 \%$ of the lesions are cured with one surgical excision, and $13 \%$ with a second excision. ${ }^{7}$ These cases involved lymphangioma of chest, thigh, buttock, neck and axilla; scrotal lymphangiomas were rare.

There are several reports of scrotal lymphangioma in literature, but most are subcutaneous unilocular lesions. 5,9-11 When the lesions are dispersed, the presentation is termed lymphangiomatosis. To the best of our knowledge, this is the first reported case where multilocular lymphangiomatosis have been found to affect the scrotal region. The genital lymphangioma in our patient is also complicated by cellulitis, which can usually be treated effectively with long-term antibiotic suppression. ${ }^{6}$ However, chronic infection from rupture of recurrent lesions, the negative psychological impact to the patient, and confinement of lesions to the scrotum led to the decision of total scrotectomy and split-thickness skin grafts (STSG) reconstruction, with a novel application of VAC dressing to promote healing. Sadikoglu and colleagues treated a case of cutaneous scrotal and penile lymphangioma en bloc resection of the lesion down to the external spermatic fascia of the scrotum and Buck's fascia of the penis, followed by reconstruction with STSG. ${ }^{9}$ Postoperative follow-up of this patient revealed 


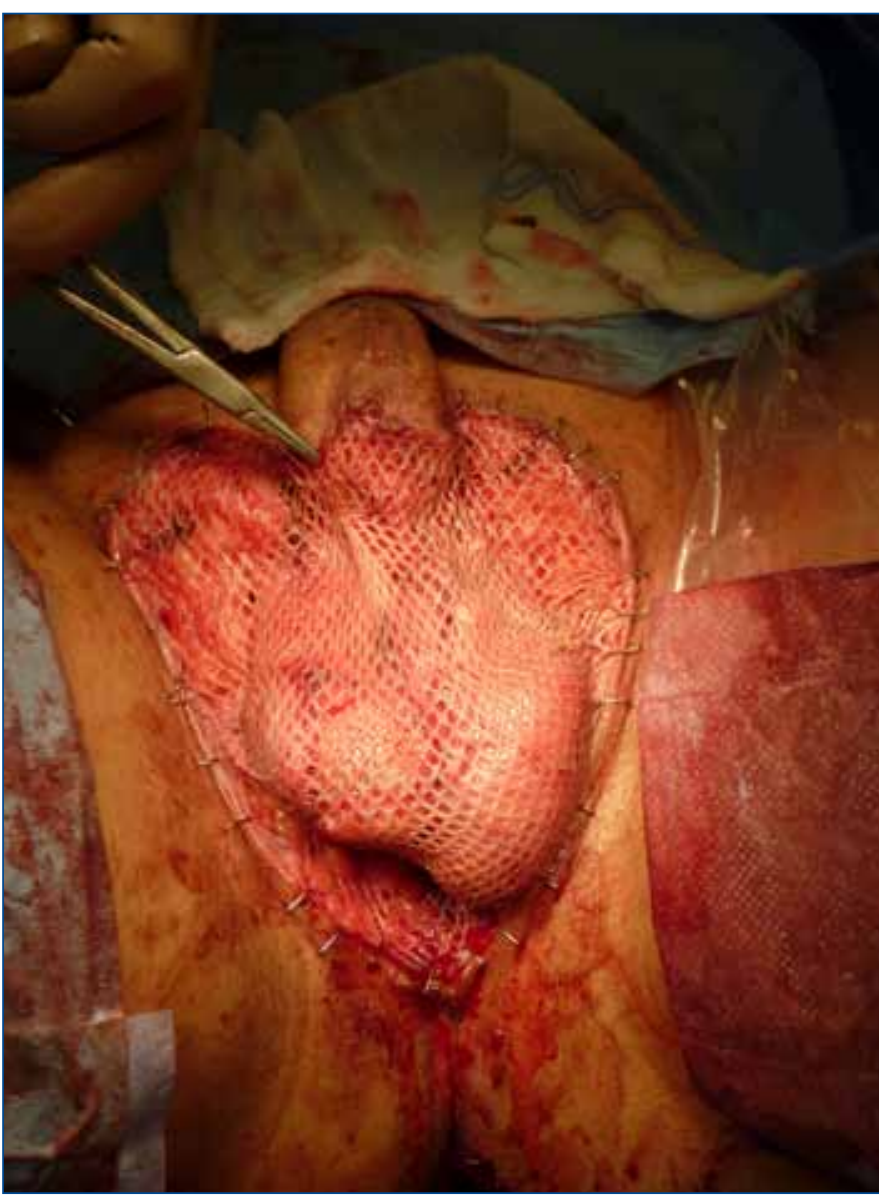

Fig. 3. Intraoperative photograph showing the split-thickness skin graft covering the testes.

well-adapted skin grafts, and the absence of penile or scrotal tenderness, pain, erectile dysfunction or recurrence of any lesions. Demir and colleagues ${ }^{5}$ and Yagmurlu and colleagues ${ }^{11}$ reported cases of scrotal lymphangioma circumscriptum involving subcutaneous tissue layers, where the lesions were removed along with subcutaneous tissues and successfully prevented recurrences after STSG reconstruction and z-plasty skin flap closure, respectively. Hence, surgical excision is a safe and effective method for treating genital lymphangiomatosis.

In cases where tissue loss is significant, the method of primary intention healing whereby the wound is suture closed becomes impossible, and surgical treatments using skin flaps or grafts are preferable. ${ }^{12}$ Appropriate contact between the skin graft and recipient bed is crucial to graft survival, and tie-over bolster dressing is usually enough to secure the graft in place over flat, non-granulated and non-motile recipient beds. ${ }^{13}$ When the wounds involve surfaces that are irregular, exudative, or subject to repeated motion, grafting becomes more difficult, and VAC is the more effective technique in securing grafts onto recipient beds. ${ }^{13}$ The device consists of an open-cell foam with an embedded evacuation

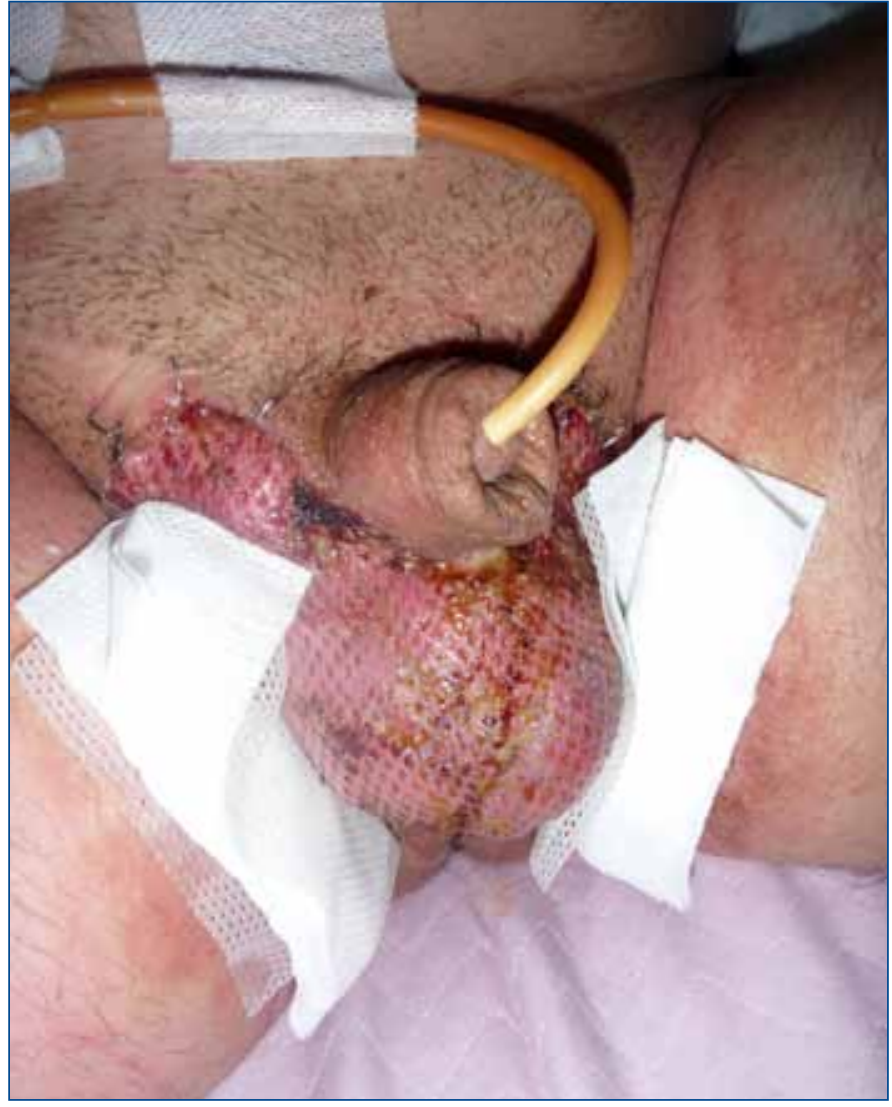

Fig. 4. One-month postoperative photograph showing the reconstructed scrotum.

tube. When subatmospheric pressure is applied through the evacuation tube, the pliable sponge ensures even pressure distribution over the site, and allows for movement in the recipient site. ${ }^{13}$ The VAC increases tissue granulation and blood flow to the wounded area, reduces bacteria counts by preventing fluid collection, and promotes graft survival. ${ }^{12}$ The reduced separation between the recipient bed and graft created by the VAC encourages faster fibroblast and collagen deposition. ${ }^{12}$ Schneider and colleagues ${ }^{13}$ reported the use of VAC to secure skin grafts in more than 100 patients over five years in various areas of the body, including feet, lower extremities, perineum, genitalia, trunk, hands, face and scalp. They found no case of skin graft loss due to fluid build up beneath the graft, which had been a common problem with tie-over bolster dressing. In cases where reconstruction of the penile shaft is involved, the sponge is cut into a ring-shape with a slit that could be opened temporarily to place around the penis, and the rings are placed one on top of another until the entire penile shaft is covered..$^{14}$ Maguiña and colleagues ${ }^{15}$ and Weinfeld and colleagues ${ }^{14}$ did, however, report minor complications of graft loss due to bleeding, shearing, infection and VAC system leak, but none of these complications compromised the quality of genital reconstruction or the health of the patient. 


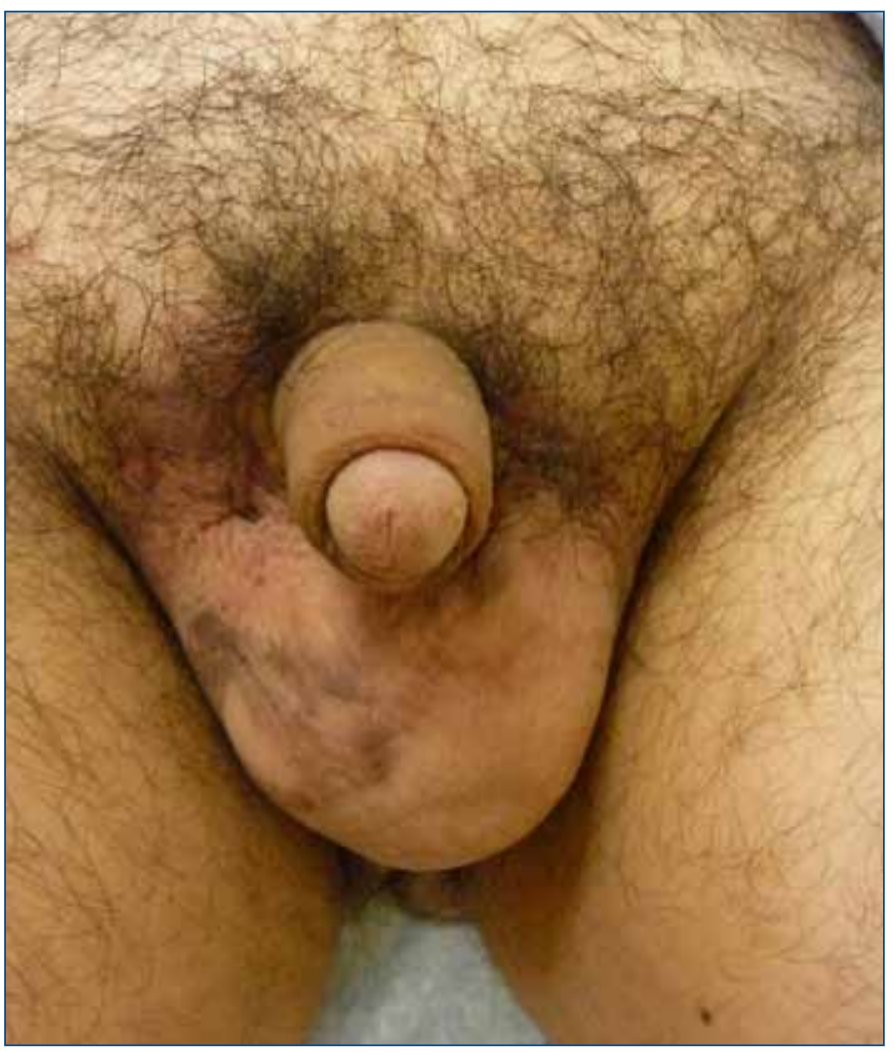

Fig. 5. Six-month postoperative photograph showing the reconstructed scrotum.

The alternative method to STSG is skin flaps, but STSG is more effective in preventing recurrent lymphatic malformations because it contains little reticular dermis, and therefore negligible amount of lymphatics. ${ }^{10}$ Skin contraction is minimal with STSG, in contrast to skin flaps. ${ }^{10}$ Additionally, surgical procedures involving skin flaps are oftentimes more complex, with the possibility of multiple procedures prior to adequate closure. ${ }^{15}$ Skin flaps are also much thicker than the native scrotal skin, and the higher temperature of the flaps may affect spermatogenesis. This case demonstrates that complete excision and STSG followed by VAC is an effective course of treatment for chronic scrotal lymphangiomatosis.
Competing interests: None declared.

This paper has been peer-reviewed.

\section{References}

1. Pui MH, Li ZP, Chen W, et al. Lymphangioma: Imaging diagnosis. Australas Radiol 1997;41:324-8.

2. Kocer U, Atakan N, Aksoy HM, et al. Late-Onset Superficial Lymphatic Malformation: Report of a Case and Review of the Literature. Dermatol Surg 2003;29:291-3. http://dx.doi.org/10.1046/i.15244725.2003.29064.x

3. Mulcahy JJ, Schileru G, Donmezer MA, et al. Lymphangioma of Scrotum. Urology 1979;14:64-5.

4. Lohrmann C, Foeldi E, Langer M. Diffuse lymphangiomatosis with genital involvement - evaluation with magnetic resonance lymphangiography. Urol Oncol 2011;29:515-22. Epub 2009 Nov 13.

5. Demir Y, Yenidunya S, Atabay K. Extensive Lymphatic Malformation of Penis and Scrotum. Urology 2001;58:106xviii-106xx.

6. Swanson DL. Genital lymphangioma with recurrent cellulitis in men. Int J Dermatol 2006;45:800-4. http://dx.doi.org/10.1111/i.1365-4632.2006.02782.x

7. Morey AF, Meng MV, McAninch JW. Skin Graft Reconstruction of Chronic Genital Lymphedema. Urology 1997;50:423-6. http://dx.doi.org/10.1016/50090-4295(97)00259-8

8. Flanagan BP, Helwig EB. Cutaneous Lymphangioma. Arch Dermatol 1977;113:24-30. http://dx.doi. org/10.1001/archderm.1977.01640010026002

9. Sadikoglu B, Kuran I, Ozcan H, et al. Cutaneous Lymphatic Malformation of the Penis and Scrotum. J Urol 1999;162:1445-6. http://dx.doi.org/10.1016/S0022-5347(05)68336-X

10. Vikicevic J, Milobratovic D, Vukadinovic V, et al. Lymphangioma Scroti. Pediatr Dermatol 2007;24:654-6. http://dx.doi.org/10.1111/j.1525-1470.2007.00557.x

11. Yagmurlu Y, Gokcora IH, Duran E, et al. A Children's disease of rarity: "Scrotal Lymphangioma Circumscriptum." Int Urol Nephrol 2004;36:229-33. http://dx.doi.org/10.1023/B:UROL.0000034668.75841.c2

12. Morykwas MJ, Argenta LC, Shelton-Brown El, et al. Vacuum-Assisted Closure: A New Method for Wound Control and Treatment: Clinical Experience. Ann Plast Surg 1997;38:563-77. http://dx.doi. org/10.1097/00000637-199706000-00001

13. Schneider AM, Morykwas MJ, Argenta LC. A New Reliable Method of Securing Skin Grafts to Difficult Recipient Bed. Plast Reconstr Surg 1998;102:1195-8. http://dx.doi.org/10.1097/00006534199809040-00045

14. Weinfeld AB, Kelly P, Yuksel E, et al. Circumferential Negative-Pressure Dressing (VAC) to Bolster Skin Grafts in the Reconstruction of the Penile Shaft and Scrotum. Ann Plast Surg 2005;54:178-83. http:// dx.doi.org/10.1097/01.sap.0000143606.39693.3f

15. Maguiña P, Palmieri TL, Greenhalgh DG. Split thickness skin grafting for recreation of the scrotum following Fournier's gangrene. Burns 2003;29:857-62.

Correspondence: Dr. Chris Nguan, Department of Urologic Sciences, University of British Columbia, Gordon \& Leslie Diamond Health Care Centre, Level 6, 2775 Laurel St., Vancouver, BC V5Z 1M9; fax: 604-875-5604; chris.nguan@ubcurology.com 